\title{
SÍNDROME DE TOURETTE NA ODONTOLOGIA: RELATO DE CASO
}

Lucas Trevisan SUZZIN, Priscila BRENNER, Aguinaldo Coelho de FARIAS

A Síndrome de Tourette (ST) envolve fatores genéticos e é de natureza neuropsiquiátrica, porém é um distúrbio de etiologia ainda desconhecida. É caracterizada por fenômenos compulsivos (tiques motores e verbais), déficit de atenção, hiperatividade e fenômenos automutilatórios. As contrações musculares rítmicas inerentes à enfermidade representam um fator de risco aumentado para o desenvolvimento de Distúrbio Temporomandibular (DTM). Este trabalho objetiva discutir o papel da odontologia no atendimento de pacientes com ST por meio do relato de um caso clínico. Paciente de 24 anos procurou o especialista em DTM e Dor Orofacial (DOF) com queixa de desgaste dentário acentuado e dor em região de masseteres bilaterais. Após a realização do tratamento com placa oclusal de estabilização e exercícios mandibulares o paciente apresentou melhora para queixa de dor. O paciente permanece usando a placa oclusal à noite para controlar o desgaste dos dentes pelo bruxismo e está em acompanhamento por três anos. Conclui-se que 0 cirurgião-dentista tem um papel importante no atendimento multidisciplinar do paciente com ST, melhorando sua qualidade de vida.

Palavras-chave: Síndrome de Tourette; tiques; Síndrome de Tourette na Odontologia 